\title{
The Cogent Reasoning Model of Informal Fallacies
}

\section{Daniel N. Boone Indiana University of Pennsylvania}

\begin{abstract}
An informal fallacy is a reasoning error with three features: the reasoning employs an implicit cogent pattern; the fallacy results from one or more false premises; there is culpable ignorance or deception associated with the falsity of the premises. A reconstruction and analysis of the cogent reasoning pattems in fourteen standard informal fallacy types plus several variations are given. Defense of the CMR account covers: a general failure to apply the principle of charity in informal fallacy contexts; empirical evidence for it; how it explains Walton's point that there are both fallacious and non-fallacious instances of fallacy types; how it avoids most "relevance" problems, permits clearer taxonomizing, and promises pedagogical advantages; how it solves a "demarcation problem."
\end{abstract}

\begin{abstract}
Résumé: Un sophisme informel est une erreur dans un raisonnement qui (1) emploie une structure implicite probante (une structure qui implique logiquement une conclusion, ou qui la rend très probable), mais qui (2) se fonde sur au moins une fausse prémisse, (3) dont la fausseté provient soit d'un certain degré d'ignorance, soit de la tromperie. On reconstruit et on analyse les structures probantes de quatorze sophismes informels traditionnels et de quelques variantes de ceux-ci. On discute de l'absence typique de l'usage du principe de charité dans les contextes des sophismes informels; apporte un appui empirique à cette discussion; explique les observations de Walton selon lesquelles il y a des arguments ressemblants aux sophismes qui sont ou fallacieux, ou nonfallacieux. Cette théorie des sophismes informels evite la plupart des problènes de pertinence; permet une meilleure nomenclature; apporte des avantages pédagogiques; démontre comment elle résout un problème de démarcation.
\end{abstract}

Keywords: informal fallacies, principle of charity, cogent reasoning model of informal fallacies, Richard E. Nisbett

What follows is a systematic account of informal fallacies radically different from other accounts. An informal fallacy is defined as a reasoning error with three features: (1) the reasoning employs an implicit cogent (deductively valid or inductively strong) pattern, (2) the fallacy results from the presence of one or more false premises, and (3) there is some degree of culpable ignorance or deception associated with the falsity of the premises. Thus, the source of fallaciousness is the falsity of the premises and not the invalidity of the reasoning, unjustified appeals to "irrelevant" reasons, incorrect moves (rule violations) in argumentative discourse, or anything else specified in other accounts of informal fallacies.

This account of informal fallacies will strike many at the outset as implausible and surely wrong. Some informal logicians are willing to concede that on occasion and in certain contexts, what superficially appears to be a fallacy (i.e., what fits a certain pattern or definition of some given fallacy) is not really fallacious (a stance frequently adopted by John Woods and Douglas Walton). Further, it has been common to identify some informal fallacies as fallacious "in spite" of the fact that 
they employ deductively valid reasoning. Moreover, Douglas Walton, John Woods, Michael Wreen and others have attempted formalist approaches, trying to discern the patterns of reasoning employed in specific fallacies especially when used nonfallaciously, but they have not attempted this systematically for all informal fallacies, including fallacious cases. ${ }^{1}$ In particular, no one has maintained that all informal fallacy types involve deductively valid or inductively strong reasoning, and that their fallaciousness is a matter of false premises (unsoundness). In the speculative account of informal fallacies which follows, I make this contentious claim, and even suggest that the cogency of the reasoning employed is a major contributing factor in disguising, misrepresenting, or obfuscating the false premises, leading us to accept them as true or at least to ignore their falsity, and thus to commit the fallacy. As I will demonstrate later, this account of informal fallacies readily explains how "fallacies" are sometimes not fallacious: when the same cogent reasoning is used in a context with true premises, there is no fallacy.

Making good these claims requires some minor and harmless gerrymandering of the category of "informal fallacy." Primarily, though, what it requires are novel interpretations of several of the traditional informal fallacies. I pay more attention than usual to what is implicit in committing the various kinds of informal fallacies. The result is an extensive reconstruction of "what is really going on implicitly" when one commits that fallacy. I want to emphasize that an essential part of this account of fallacies is the realist claim that these reconstructions more accurately and adequately characterize the class of common thinking mistakes logicians have attempted to identify as fallacies. The account of informal fallacies I give here is partially empirical in nature, as I will discuss further in a later section of this paper. But to help place this account in its proper perspective, I conceive the cogent reasoning patterns along similar lines to those investigated by psychologist Richard E. Nisbett and his colleagues. In his introduction to Rules For Reasoning, Nisbett summarizes twenty years of research findings on different rule systems, including "pragmatic reasoning schemas" in contractual obligation and permission contexts, statistical reasoning, causal rules, and cost-benefit rules of microeconomic theory. "The upshot of these findings," he concludes, "is that modern cognitive science and modern educational theory must accommodate themselves to the existence of abstract inferential rules." My account of informal fallacies advances the speculative claim that modern informal fallacy theory must make the same accommodation.

\section{Preliminary Considerations}

(a) One fundamental part of my thesis is that informal fallacies employ correct or good reasoning patterns. These may be either deductively valid or inductively strong, and to simplify this thesis, I will use the term "cogent" to signify either. "Deductively valid" will mean "valid" both in the standard propositional or firstorder predicate logics, and also in extended logic formulations, particularly epistemic and deontic logics. I will not, however, attempt to develop the actual symbolic 
extended logic formulations here. The cogent reasoning patterns will be verbally expressed for the most part, with occasional symbolism to aid abstraction. Cogent patterns occurring in informal fallacies will sometimes be more specifically designated as falling in certain subcategories, for example, as "testimonial reasoning." Hereafter, I will refer to this account as the cogent reasoning model of informal fallacies (CRM).

Certainly, the most controversial element of the CRM account is the claim that cogent reasoning patterns are implicit in each fallacy type. My main goal in this paper is to provide prima facie evidence that adequate reconstructions of each fallacy can be given and that this controversial thesis could be true. But let's now begin the process of making this conjecture slightly more plausible. It seems to be a working assumption within critical thinking circles that ordinary people are very frequently guilty of invalid reasoning or bad reasoning when committing informal fallacies. Is this assumption justified? Or is it possible that people are much better native reasoners than fallacy theory gives them credit for, but unfortunately, the exact nature of the reasoning has been misunderstood by informal logicians (since much of it is implicit)? The latter possibility is the one explored here: at least in the case of the traditional informal fallacies, 1 hypothesize that people do a pretty good job of using correct reasoning, at least in Nisbett's sense: when appropriate "pragmatic reasoning schemas" are employed in a given context, the ability of subjects to make correct inferences is fairly good. ${ }^{3}$ According to CRM, the breakdowns we should recognize as informal fallacies-where the deception, confusion, manipulation, and gullibility associated with fallacies occurs-is in the area of false premises accepted as true, not in the areas of invalid or irrelevant reasoning.

There is a certain irony here. Many informal logicians have developed "principles of charity" which operate by guiding interpretations of incomplete arguments to supply premises which make the arguments cogent. Why does it seem like this approach has been wholly abandoned by informal logicians when the subject is informal fallacies? And for what reason? And further, is that reason sufficient? Again, I raise these questions now merely to soften anticipated resistance; later I will examine them more fully.

(b) I will maintain a distinction between formal and informal fallacies. Others frequently include discussions of such fallacies as "affirming the consequent" and "denying the antecedent" within the discussion of other traditional fallacy types. If the category being discussed is "fallacies," then this seems acceptable. However, if the category is that of "informal fallacies" and the term "informal" has significant content, then including "formal" errors in the category is curious. Adequate formal machinery exists for the effective criticism of formal reasoning mistakes. The subject of informal fallacies has often focussed on reasoning mistakes thought not to be analyzed sufficiently as a formal reasoning error. Thus, I will carry on that fairly common trend by ruling out of court the inclusion of any fallacies which are primarily cases of deductive invalidity. This minor gerrymandering is not intended to initiate any turf wars over the label "informal fallacies." If 
someone insists, they can still be included, but at least let us recognize the difference between deductive invalidity as the primary criticism of a fallacy, and something else. I argue below that the preponderance of traditional informal fallacies are of the "something else" variety. Thus, at the minimum (to avoid the turf war), I could express the CRM thesis in this way: a preponderance of traditional informal fallacies can be systematically described as involving cogent reasoning, though some few involve deductively invalid reasoning. At the maximum, if the reasonable recommendation is accepted that "informal" fallacy means a reasoning mistake which is "not formal," then the thesis remains the universal one first propounded: all informal fallacies involve cogent reasoning.

(c) Many fallacies are statistical in nature. While many of them might succumb to the model of analysis presented here ${ }^{4}$, I prefer to deal with them within the context of deviations from proper statistical reasoning. These include such fallacies as Hasty Generalization (Small Sample), Unrepresentative Sample, False Cause, and post hoc fallacies. Questionable Analogy is included below because it seems to have both statistical and nonstatistical uses.

(d) The very same pattern of cogent reasoning is also employed in nonfallacious cases, i.e., when the premises and background assumptions are true. This must be true in order to produce a general level of understanding and trust in that reasoning pattern. On Nisbett's model, rules are "pragmatically useful rules that most people will have naturally induced in at least a rudimentary form from everyday experiences." An informal fallacy, then, is parasitic on such cases. First, trust in the cogent reasoning pattern is established, and the pattern then becomes a habitual mode of reasoning through application to everyday cases in which the reasoning is sound. Second, the habitual application later leads us to overlook the falsity of the premises when the pattern of reasoning is misapplied in other contexts, creating an informal fallacy. Thus, the fallacy results, at least in part, from a kind of uncritical giving in to habit.

(e) The CRM account must be seen as a speculative hypothesis about informal fallacies. It purports to have empirical consequences and testability, and to imply a realist claim about the psychological existence of the cogent reasoning patterns.

(f) There may be some few occasions when all of the premises of the fallacy are explicit and the cogency of the reasoning needs no reconstruction. Such cases will be parasitic on the main account, and still considered fallacies if the premises are false. The CRM account does not insist that the premises must be implicit (rather than explicit). It is just a fact that they normally are.

Furthermore, for some of the fallacies it isn't just any of the premises which will create a fallacy by being false; rather, it may be one pivotal premise in particular that does the damage. ${ }^{6}$ These will be indicated within each fallacy analysis, and the significance of pivotal premises discussed in Section IV. This concern relates to the third feature in the above definition of informal fallacies. Culpable un- 
soundness results in a fallacy, rather than mere possession of a false premise. The manner in which the false premises come to be propounded or accepted will serve to demarcate fallacies from nonfallacious valid-but-unsound cases. Discussion of this is also reserved for Section IV.

\section{Accounts of the Individual Informal Fallacies}

Let us now turn to an account of some of the traditionally identified informal fallacies. Hundreds of distinct fallacies have been discussed historically, and no effort will be made to cover most of them. Instead, 1 have selected a number which seem to comprise a set of "classical" fallacies-those commonly encountered in fallacy classification systems. It will be an interesting long-term goal to apply the CRM thesis to every fallacy type historically presented just to see how far CRM can go. But such a controversial thesis should perhaps be tested on a smaller set before engaging in such an ambitious project. A disclaimer needs to be made at the outset, however. Since Hamblin's rallying critique in 1970, there has been abundant fruitful work on informal fallacies, including the presentation of often subtle variations in concrete cases for each specific fallacy type. Thus, the accounts of each fallacy type given below may be partially oversimplified: they may not cover all possible variations within a particular fallacy type. My aim here is to give at least one correct account for certain central, clear examples of each fallacy covered (though in some cases variations are included), and to ignore for now the full range of possible variations. My main goal will be to show that the thesis can be maintained for at least typical, central cases of each informal fallacy type; addressing the multitude of variations must wait for future occasions. To repeat: the thesis is that for each informal fallacy type, a plausible account can be given in which the implicit reasoning is deductively valid or inductively strong, and the fallacy the result of false premises.

I will begin with the easier and more obvious fallacies-those in the literature already sometimes noted as employing valid reasoning patterns-and then move on to more controversial fallacies. For each fallacy, I will present and discuss the implicit cogent reasoning pattern, often by reference to examples, and when appropriate, I will also discuss other relevant issues.

Admittedly, the cogent reasoning patterns may seem to import fairly complex implicit structures into fallacy examples, and there may be a concern that I am imposing implicit structures which simply "are not there." Justification that these are plausible reconstructions of the reasoning implicit in examples of fallacies will come later, in Section III. For now, the reader's patience is requested: before arguing that it should be done, it is probably helpful to set forth in some detail exactly the kind of reconstructions of reasoning I have in mind. 


\section{A. Informal Fallacies-Deductively Valid Reasoning Patterns}

\section{False Dilemma}

\section{Implicit cogent reasoning pattern:}

\section{Either $A$ or $B$.}

[We ought not to want $A$ to be true, or we ought not to let $A$ be true, or simply, $\mathrm{A}$ is not true.] (implicit premise)

So, [We ought to want the truth of $B$ or we ought to accept the truth of $B$.] (implicit conclusion)

In typical cases of false dilemma, we are explicitly presented with two choices. For example, we may be told "either we adopt managed health care or we will erode the quality of life of all Americans." The point of that exclusive disjunctive statement, however, is to present us with a premise in an argument. The implicit conclusion is that we should adopt or favor a managed health care system. To reach that conclusion, we need to add the further implicit premise that we shouldn't want to erode the quality of life of all Americans. In other words, the explicit statement is a premise, and there is also an implicit premise and an implicit conclusion. This, of course, is a deontic version of a valid pattern of disjunctive syllogism (though some simple examples of false dilemma may employ the propositional logic version). The fallacy lies in the falseness of the first explicit premise. This premise is a false dichotomy, or false set of alternatives, and is the pivotally false premise in false dilemma fallacies. here are other choices between the two extremes presented in the disjunction. In the example, perhaps there are alternatives to managed competition health care systems that are preferable, or even if things were left the way they are, Americans might suffer some erosion of the quality of life, but not a serious erosion.Thus, this first premise is false.

Variations: One simple variation sometimes noted by informal logicians is to use an "If . . . then ..." premise in place of the "Either . . . or ...." The example would have worked just as well (and the premise been just as false) with the statement, "If we don't adopt a managed competition health care system, then our public finances will be strained to the point of eroding the quality of life of all Americans." In this case, the reasoning pattern, with the same implicit premise and implicit conclusion, is a deontic modus tollens.

\section{Straw Man}

The intent of a straw man fallacy is to provide support for a favored claim, or undercut support for a disfavored claim, by caricaturing an opponent's position or point of view to make it seem false.In simple cases, this involves the following reasoning pattern:

\section{Implicit cogent reasoning pattern:}

(1) If $D$ is a correct description of point-of-view $P$, then $P$ is false. 
(2) $D$ is a correct description of point-of-view $P$.

(3) So, $P$ is false.

In typical cases it is the falsity of premise (2) (the pivotal premise) that constitutes the fallacy.

Variation: Many cases of straw man could also be analyzed as a form of the false dilemma fallacy. Here's an example:

The Excuse-Making Industry . . . initiated a quiet revolution in the criminal justice system. Its proponents managed to rout the last of those who believed that the system's purpose was to apprehend and punish criminals. Instead, the Excuse-Making Industry was able finally to institutionalize its long-cherished dream: not the punishment, but the rehabilitation of criminals ... The criminal is not responsible for his actions ... . He should be forgiven, or treated therapeutically, or placed in a better environment, or counseled to 'cope' with his uncontrollable inner demons. But he must not be held accountable for his actions-and, under no circumstances, punished for what he 'couldn't help'....?

In this example, we have the same reasoning as false dilemma. The disjunctive premise (simplified) is that you either accept the ridiculous view of rehabilitation advocated by the Excuse-Making Industry or you accept the punishment-of-criminals view advocated by the author. The implicit premise is "You shouldn't agree with that ridiculous view." The implicit conclusion is "You ought to agree with the author's view." The pattern is the same deontic valid disjunctive syllogism pattern. The fallacy is the same, too: there is a false dichotomy between the opposition view and the favored view. This false dichotomy is created by the distortion of the opposition view. Thus, the fallacy is committed through the acceptance of a deceptively false pivotal premise.

While straw man may often be just a variation of false dilemma, it has traditionally been treated as a separate fallacy because it is such a common type. False dilemma is more general, setting up false choices between lots of different things: social policies, values, actions, situations, etc. Straw man sets up a false choice between one or more (distorted) opposing viewpoints and the speaker's viewpoint, and is thus somewhat restricted to the context of disputes and disagreements about issues.

\section{Slippery Slope}

\section{Implicit Cogent Reasoning Pattern:}

If $A$, then $B$.

If $B$, then $C$

If $C$, then $D$

If $D$, then $E$

[We should not want $E$ to be true] (implicit premise)

So, [We should not want $A$ to be true, or we should not let $A$ be true.]

(implicit conclusion) 
Here's an example:

If active euthanasia were allowed on the basis of life's being unduly burdensome, each of the above circumstances [quadriplegia, the loss of a limb, terminal illness, the loss of a loved one, or just the fear of being a burden] could qualify; each could be considered so burdensome that death would seem a relief. Based on that reasoning, life would no longer have an intrinsic value but one subject to the changing tides of feelings and circumstances. ${ }^{8}$

In this example, the implicit premise is, "We do not want to end up with a devaluation of life." The implicit conclusion is, "Therefore, we should not take that first step of allowing active euthanasia." The reasoning is deontically valid, and the fallacy seems to reside in the falsity of one or more premises. But which one? That's hard to say, which is why this is such an effective and pernicious fallacy. Leaping from the first step to the last step is clearly false. It seems absurd that active euthanasia of terminally ill patients will inevitably result in a total devaluing of all human life. But when the slippery slide is broken down into little steps, it isn't so obvious which one is false. Is it so clear that the difference between terminally ill patients and severe burn victims or certain kinds of handicapped people is so great as to disqualify the latter from active voluntary euthanasia? And so on. How do you draw the line, except arbitrarily? The answer is, however difficult it may be to draw the line, we do draw it and not arbitrarily. It may be hard to articulate what the salient differences are between "terminally ill" patients and others, but there do exist important differences which block the slippery slope reasoning. Thus, we need not specify exactly which premise is the false one. It suffices to point out that the claim of an inevitable slide from the first step to the last is false, or at least very doubtful (it is the chain of reasoning, which can be of any length, which is pivotal in this fallacy).

Variations: One variation of this fallacy is a positive version. It is claimed that by taking a first step of some inevitable sequence, you will end up in paradise, not disaster, therefore do take that first step. For instance, "subscribing to a certain magazine on investment and money management will help you make better uses of your money, which will allow you to accumulate a small fortune quickly, which will allow you to retire as a multi-millionaire by the age of 35 . Therefore, you should fill out and send in this magazine subscription form at once."

The implicit cogent reasoning in this variation seems to be that of goal-oriented problem-solving. Even chimpanzees seem capable of it: recall the famous experiment of chimps figuring out how to move a box, in order to stand on it, in order to be high enough to use a stick, in order to retrieve bananas. Here's the implicit cogent pattern:

If $S$ takes step $A$, that will enable $S$ through a chain of steps to reach goal $G$. If $S$ wants to reach goal $G$, and doing A is a sufficient way (through the steps) to get to $G$, and also the best way available to get to $G$, then $S$ ought to do $A$. 
$S$ wants to reach goal $G$, and no other way besides doing $A$ seems better.

So, $S$ ought to do $A$.

A second variation of this fallacy is called the fallacy of the heap. If you have just one, single, tiny grain of sand, then you don't have a "heap" of sand. If you don't already have a heap of sand, then if you add just one more grain of sand to what you already have, then that won't give you a heap. So, no matter how many grains of sand you add, one-at-a-time, you can never get a heap of sand.

This reasoning is far-fetched, exploiting the valid reasoning of the slippery slope fallacy combined with the vagueness of the term "heap" to reach its faulty conclusion. Again, the appropriate criticism is to point out the falsity of the chain: starting with one grain of sand and ending with ten tons of sand does give you a "heap" of sand at the end of the process, even if you do it one-grain-at-a-time.

The fallacy of the heap is seldom applied to authentic cases in the literature. Most examples are as outrageous as the heap of sand example. But it does seem like this might be the reasoning underlying "one-more-for-the-road" reasoning: if you're not already too drunk to drive, then one more drink isn't going to hurt you. Other "weakness of will" situations are similar: having one more cigarette before you quit for good, or one more cookie before you start your diet, etc.

Actually, these cases are very similar to false dilemma. As pointed out earlier, false dilemma fallacies can be committed with an "If . . then ...." That means a false dilemma is equivalent to a very short slippery slope (which usually has two or more conditional premises), with just one conditional premise. As an example, consider the following:

Standard false dilemma:

"Either I'm already too drunk to drive, or one more drink won't hurt me. I'm not already too drunk to drive. So, one more drink won't hurt me."

\section{Conditionalized false dilemma:}

"If I'm not already too drunk to drive, then one more drink won't hurt me. I'm not already too drunk to drive. So, one more drink won't hurt me."

Fallacy of the heap/slippery slope:

Same as conditionalized false dilemma, except for the difference that this may be the fifth time you have said, "OK, but this has got to be the last one." The heap/slippery slope category suggests there has to be some kind of sequence or chain of steps leading to disaster.

So, how should we classify cases like this, as slippery slope or false dilemma? A problem often noted with traditional accounts of informal fallacies is that the categories begin to blur and overlap like this, which is seen as a serious flaw in the classification system or definition of informal fallacies. ${ }^{9}$ On the account given here, this is not a flaw, but something to be expected, and even "predicted" by the 
theory. If the cogent reasoning patterns employed in different fallacies are identical or logically-equivalent, then there should be cases which are cross-classified, or hard to classify, unless there are other distinguishing criteria. Straw man, for example, seems to have a distinct feature of narrowly focussing on the distortions of opposing viewpoints, which sets it apart from other cases of false dilemma. But false dilemma and slippery slope apply to the same range of cases, the difference being merely one of length of the conditional chain. When this difference is blurred, then so is the possibility of a clear category assignment.

\section{B. Informal Fallacies-Testimonial Reasoning Patterns}

In this next section, I will consider fallacies which employ inductively strong reasoning patterns in the process of giving "testimony." These will represent certain ways we reason about the reliability of the testimony of others, influencing our thoughts and actions. The nature of an informal fallacy will remain the same: a cogent (in these cases, inductively strong) reasoning pattern with a false premise.

\section{Authority}

\section{Implicit Cogent Reasoning Pattern:}

Most people who are legitimate authoritative experts about a subject have true opinions about many uncontroversial questions in that subject.

This person is a legitimate authoritative expert about this uncontroversial question.

Therefore, this person's opinion about this question in this subject is probably true.

Opinions of "authorities" are generally reliable, or more likely to be true than the guesswork of amateurs. After years of satisfaction in taking my cars to a certain mechanic, if she says that noise is the water pump going bad, then I'll believe her.

The general rule expressed by the first premise is a testimonial rule regarding the trustworthiness of a certain type of testimony. Moreover, the reasoning exhibited in this rule is inductive in nature. Testimonial rules are treated as inductive in this account because we know that any authority can be wrong sometimes, thus the best that good, expert opinion can give us is some assurance that the opinion is probably true. There is no guarantee that it must be true.

Douglas Walton presents an analysis of this fallacy in which he lists six requirements and five sub-requirements for deciding whether or not someone is a legitimate authority. ${ }^{10}$ These are valuable requirements for arguing the truth or falsity of the second (and pivotal) premise in the implicit cogent pattern. Generally, Walton's approach in this case seems consistent with the CRM thesis: an authority fallacy uses a false premise (appealing to the opinion of someone who is not a 
legitimate expert, or making an appeal to an expert on a controversial claim about which experts disagree) within a cogent reasoning pattern. Given the approach to this fallacy taken by Walton and others, it seems incorrect to regard the authority fallacy as a fallacy of relevance. Van Eemeren and Grootendorst also object to the "Standard Treatment's" classification of this fallacy, as well as ad hominem, ad baculum, ad ignorantiam, ad misericordiam, and ad populum, as fallacies of relevance. Among other things, they decry the lack of definition of "relevance" and the lack of explanation of the connection between relevance and logical validity." Prima facie, appeal to an authority is a relevant dialectical move. What seems in question in fallacious cases is whether or not the authority is really legitimate, and the question really uncontroversial, and so, examining the falsity of the second premise in the cogent reasoning pattern seems more directly to the point than considerations of when such an appeal becomes irrelevant. That is, the fact that it is false that the authority is legitimate or the issue uncontroversial among experts is logically prior to and explains both why the appeal to that authority is irrelevant and why a fallacy has occurred.

Variations: One variation is what we can call a practical reasoning pattern, that is, reasoning about how we should act or what we should do:

For certain kinds of situations, most people who are admirable, respected, or even worshipped behave in ways worthy of imitation.

This situation is of a certain kind, and this person is admirable, respected, etc.

Therefore, this person's behavior should be imitated.

We are often reminded that modelling correct behavior is important for parents, teachers, and others in positions of authority and trust. We tend to view certain people as models and to trust their judgments about how we should act (or trust the judgment "implied" by their behavior), at least in contexts where that behavior is appropriate and desirable. One problem with this inference is deciding on the limits of our expectations with respect to the range of contexts over which the expectations are reasonable. For example, given our society's present trend of exposing all aspects of the lives of celebrities, we are often disillusioned when our heroes turn out to have feet of clay in some contexts. That shouldn't totally invalidate this reasoning pattern.

A fallacy is committed when we mistakenly accept the second (pivotal) premise in this pattern as true. Hindsight will often inform us that we should have heeded those warning signs in deciding to admire or respect someone, or limited our expectations about the range of situations in which we realistically should have expected "heroic" behavior from this person.

The authority fallacy can be committed in other ways than by appealing to celebrities. Sometimes groups of experts, such as "doctors," may be appealed to as authorities. Sometimes tradition may be presented in an authority's role: if a 
business or organization has been in existence for a long time, or if a certain way of doing things has worked well for many years, then that may be presented as grounds for some belief or action.

The ad populum fallacy of bandwagon or popularity is similar to authority reasoning. The fact that almost everyone believes or does something is weak presumptive evidence others should, too. James B. Freeman endorses this view and also attributes it, with qualifications in terms of "common knowledge" rather than simple popularity, to Nicholas Rescher and Trudy Govier. ${ }^{12}$ However, Freeman's analysis of the fallacy as inflation of the weight of the evidence is suspect. He presents an earlier view of his that the appeal to popularity is "not so modest . ... It claims that because a belief or action is popular, it must be true or right." ${ }^{13} \mathrm{He}$ subsequently weakens the consequent clause to "... we have sufficient reason to accept that belief as true or that course of action as right." 14 But this weakened form is still too strong for Freeman. He regards appeals to common knowledge as a "proper source of presumption," i.e., in some way nonfallacious. But Freeman wants to distinguish appeals to popular opinion from appeals to common knowledge, and considers the former always fallacious (inflating the weight of the evidence) and the latter always good presumptive evidence. I suggest that the popularity fallacy is a matter of conflation, not inflation. Unjustified conflating of popular opinion with common knowledge is what leads to the fallacy. Here's the $\mathrm{ad}$ populum implicit cogent reasoning pattern:

(Most / Many / The majority of / A significant number of / A few) cases of popular opinion in the present circumstances reflect common knowledge about correct beliefs and proper actions.

Common knowledge beliefs are probably true and common knowledge recommends actions which are probably proper.

This is a case in which popular opinion says believe or do $A$, and the proper circumstances are present.

Hence, $\mathrm{A}$ is probably true or proper.

The point is that we take popular opinion as a pragmatic sign of common knowledge, and act accordingly. I'm reminded of a pragmatic rule I once heard for getting by in the Russian economy: "If you see a line of people, get in it. It doesn't matter what you end up buying when you get to the front of the line-you can always trade it for something you really need."

Individuals vary widely in their estimations of the reliability of popular opinion in reflecting common knowledge in different contexts; thus, there needs to be a range of quantifiers in the first premise. And common knowledge, unlike other sorts of knowledge, may only consist in probably true beliefs or probably proper actions. Thus, the inference is doubly-hedged, and our confidence in the conclusion can vary greatly. Unlike Freeman, however, I am unwilling to say that appeals to popular opinion are universally fallacious. We must often act with nothing more to guide us than popular opinion-we simply lack the resources on many occasions to satisfy Freeman's more stringent criteria of common knowledge. Acting 
on this basis seems hardly irrational or fallacious, if it's all we have to base our judgments on in the present circumstances. As Yossarian says in Catch 22, if everybody's doing it, I'd be a damn fool not to.

\section{Ad Hominem Abusive}

In some ways, the ad hominem fallacy is the reverse of the previous fallacy, authority. In this case, "bad" personal characteristics of people are used to discredit or disparage their opinions or actions. Rather than authorities to be respected, they are pariahs to be cursed and shunned. The two cogent, but somewhat weaker, reasoning patterns involved are very similar to the authority patterns as well:

\section{Implicit Cogent Reasoning Patterns:}

\section{Discrediting Opinions:}

Most people who are despicable in ways affecting their integrity and reliability on certain issues do not have trustworthy opinions about these issues. This person is despicable in ways affecting his/her integrity and reliability about the issue at hand.

Therefore, this person's opinion in this particular case probably should not be trusted.

\section{Disapproving of Actions:}

The behavior of most people who are despicable in certain ways should not be imitated.

This person is despicable in certain ways.

Therefore, this person's behavior probably should not be imitated.

These are further cogent rules of testimony and modelling. If we have knowledge of a person's dishonesty, lack of integrity, tendency to lie, and inclination to pursue selfish gain in deceitful ways, then we are well-advised to regard anything, or most things, that person says or does with a degree of skepticism. Proven lack of credibility and integrity undercuts the amount of faith we should put in someone's opinions or actions. The inferences in both cases are relatively weaker inductive patterns, but still have some degree of cogency.

Once again, the fallacy results when one or more of the premises is false. Either the "despicable" nature of the person does not really lead to untrustworthiness or the person's behavior is not despicable. In fact, because there are these two different possibilities, this pattern shows another difficulty with conceiving of ad hominem abusive arguments as fallacies of relevance. Roughly, ad hominem abusive arguments can be fallacious because the cited personal characteristics are true but irrelevant to the conclusion or because the alleged personal characteristics, whether relevant or irrelevant, are not true of the person. Alan Brinton recognizes this distinction: 
"There are two other general, and much more common, ways in which ad hominem arguments may go wrong. They correspond to two familiar questions in the evaluation of arguments, 'Are the premises true?' and 'Do they support the conclusion?' In the first place, the assertions (accusations, say) made about Jones, the adhominee, may be false (or at least doubtful). Second, the assertions made about Jones may fail to provide adequate grounds for the proposed shift in hearer's attitudes toward Jones's advocacy-of-P."Is

Unfortunately, Brinton resists calling the first form a "fallacy" because he is wedded to the view that only logical defects are fallacies. He also rules out personal insults, ridicule, and other personal attacks as fallacies (and for the same reason), even when they are "significant strategies in argumentation." ${ }^{16}$ We need not follow Brinton here, since we need not accept his narrow definition of fallacy. Thus, many classical instances of ad hominem abusive fallacies seem to involve false or distorted, rather than irrelevant, attributions of personal characteristics.

For the second class of seemingly "irrelevant" abusive attacks, the problems with relevance discussed above in connection with the authority fallacy apply in this case as well. Moreover, as Brinton astutely notes (following Aristotle), "signs of poor practical judgment, of dishonesty, or of malice toward me are grounds for discounting advice or refusing a hearing to a purported adviser." "It would be especially difficult to sort out the relevant from the irrelevant "signs" of this sortthe range of behaviors which might be counted as malicious, for example, seem quite extensive. Of course, this is a problem, too, for the CRM account. How are we to decide whether or not a certain way of being despicable affects someone's reliability or integrity on certain issues? But it seems to be a specific problem, rather than the general problem facing other fallacy theories. If a fallacy theory promotes relevance considerations as a general means of categorizing informal fallacies, then it has a burden of proof to explain the general nature and conditions of relevance. In the CRM account, all that is required (though it is still no small task) is to explain in some few particular cases how certain despicable personal characteristics may or may not affect that person's credibility or reliability in certain circumstances.

\section{Ignorance}

A few fallacy theorists have held the view that the argument from ignorance has both fallacious and nonfallacious instances. Douglas Walton locates himself, as well as Richard Robinson and Michael Wreen, in that camp, and then comments, "Generally, however, the argument from ignorance continues to be maligned ... "18 Throughout his book Arguments from Ignorance, Walton defends the thesis that arguments from ignorance often have value and frequently represent plausible lines of reasoning. The CRM account, of course, welcomes Walton's defense of this particular point, even if Walton prefers a different account of informal fallacies. Walton comes even closer to a CRM-style analysis in Chapter 8, however, when he begins to consider argument forms or schemes of the argument from 
ignorance. The wealth of examples and analyses provided by Walton make it likely that a number of distinct cogent reasoning patterns will be necessary to capture the multiplicity of nuanced structures in ignorance arguments. What follows is at least an initial attempt for one main category.

Suppose your dog, a full-grown St. Bernard, is missing. You think you may have left the dog asleep in the car. So, you ask a competent adult who is standing by the car to check. She looks in the car and reports, "No, Bernie's not in the car." It is cogent testimonial reasoning for you to draw the conclusion that Bernie is not in the car. Notice that there are two important factors involved in this case of negative evidence. Here, the absence of evidence for a claim (1) by a competent investigator, (2) in circumstances permitting thoroughness, can be taken as evidence against it.

In similar cases, the absence of evidence against something by competent investigators can be counted as evidence for it. Such cases involve special circumstances because the absence of evidence counts for something not merely because of the competence of the investigator, but also because of the possibility of completeness or thoroughness of the investigation in such circumstances. The first cogent reasoning pattern incorporates both of these factors.

\section{Implicit Cogent Reasoning Pattern:}

If a sufficiently thorough and completely competent investigation is carried out and $A$ is true (false), then evidence in favor of (against) $A$ should probably turn up.

This is a sufficiently thorough and completely competent investigation, and no evidence in favor of (against) $A$ has turned up.

Therefore, $A$ is probably false (true).

The second premise is pivotal. One form of the informal fallacy of ignorance occurs when the first part of the second premise is false. Many situations do not allow an inference from the absence of evidence to something being the case, even if the investigation is competently done-that is, in many cases it is false that the circumstances permit the desired thoroughness, or that such thoroughness has yet been achieved. For example, the failure of medical science to conclusively rebut homeopathic medicine represents not a failure of competence by medical researchers, but a (perhaps temporary) failure to achieve the necessary thoroughness in a complex set of research studies. Thus, it would be a fallacy of ignorance for someone to argue the plausibility of homeopathic medicine on the grounds that medical research has failed to prove it incorrect.

A second form of the fallacy occurs when the "competence" part of the second premise is false. Let us suppose the situation to be one permitting a thorough and complete investigation. However, suppose there are reasons to doubt the competence of the investigator. For example, accepting a sensational tabloid account, involving negative evidence, about some scandal would be such a fallacy if it's the 
kind of case in which responsible journalism would most likely discover the truth. ("Were they secretly married in Reno? They're not saying....") And, needless to say, there could be fallacies in which both the competence of the investigator and completeness of the investigation are called into question.

A variation of the argument from ignorance raises worries about illegitimate shifting of the burden of proof. What is frequently happening when people commit the fallacy of ignorance is that they are trying to shift the burden of proof onto the opposition. They are saying, "It is totally your responsibility to prove me wrong, and if you can't, l'm right!" Or they are saying, "It is totally your responsibility to prove yourself right, and if you can't, I'm right."

The cogent reasoning pattern which underlies this fallacy variation derives from cases in which there are good reasons for suspicion about the sincerity or reliability of the speaker. Consider the following example:

(State police officer to arrested teenage driver): "You say this is your parents' car you're driving and they know you have it, but you can't find the registration, and now you've refused to give me their names and phone numbers.... So, I have to tell you, I don't think you're telling me the truthI think you have taken this car without the owner's permission, whoever the owner really is."

It is plausible in this case that the officer is justified in reaching a fairly strong conclusion, disbelief instead of suspension of belief. Assertions and claims frequently carry with them larger burdens of proof, especially in circumstances where lying or misrepresentation is a serious possibility. Thus, in such cases, there is the following cogent pattern:

These are circumstances in which you (the advocate for $A$ ) may be insincere, and if you assert $A$, then you better be able to give good reasons to believe that $A$ is true, or else you are probably asserting $A$ insincerely.

You are asserting $A$, but have not given any reasons to believe that $A$ is true. If you are asserting $A$ insincerely, then $A$ is probably false.

Hence, $A$ is probably false.

A fallacy results when this cogent reasoning is misapplied in circumstances where suspicion of the speaker is inappropriate. Nevertheless, when put on the spot to defend a position, it is easy for things to become blurred, so that it may not be clear that the speaker's sincerity is not at stake. This may lead those engaged in the dispute to assume that the speaker must measure up to an unreasonably high standard in order to discharge the burden of proof. This helps to explain the "tugof-war" examples discussed by Walton. ${ }^{19}$ White asks Black, "Why $A$ ?" who replies, "Why not- $A$ ?" and so on. The strategy in such a tug-of-war is to put the other parties on the defensive by posing a challenge to their sincerity. When Black asks White, "Why not- $A$ ?" rhetorical gamesmanship may be occurring along the lines of "You can't be serious! How can you doubt that $A$ ? What possible reasons could you have for doubting $A$ ? Unless you can give such reasons, you must be 
insincere, .. etc." The strategy is to assimilate the present context to contexts in which questioning the arguer's sincerity is legitimate. Thus, the fallacy results from the falsity of the first premise in the cogent pattern because these are not circumstances where the speaker's sincerity is genuinely in question, or in which the speaker must assume a larger burden of proof.

\section{Informal Fallacies-Practical Reasoning Patterns}

A traditional approach to one broad category of informal fallacies views them as primarily irrelevant appeals to emotion. It has been thought that stirring up strong emotions leads to errors in reasoning and judgment with a resultant lack of justification for changes in attitudes, actions, and beliefs. Informal fallacies, on this view, are sometimes explained as substitutions of emotions, feelings, motives, etc., for proper reasoning. Others see them as either instances of "wishful thinking," in which our desires and wishes overwhelm our reasoning, or as cases of emotional reactiveness which totally displace critical thought. Contrary to these traditional approaches, some such as Douglas Walton have made a case that emotions can work in harmony with correct reasoning: "The thesis of this book is that appeals to emotion have a legitimate, even important, place as arguments in persuasion dialogue, but that they need to be treated with caution because they can also be used fallaciously. "200 Moreover, recent neuroscience research provides evidence that emotions may be much more "rational" or "reasonable" in their nature than the tradition suggests. ${ }^{21}$

Two of the "ad" fallacies, ad hominem abusive and ad populum, traditionally categorized as irrelevant appeals to emotion were already discussed above. In this section, we will look at other "ad" fallacies for which the CRM account can be given. The major difference between these fallacies and those of the earlier sections is that the reasoning involved is primarily practical reasoning, i.e., reasoning about what actions should be taken, which often includes the ascription of moral values or other values to situations.

\section{Pity}

We've seen with earlier fallacy types that Douglas Walton believes one can find both fallacious and nonfallacious instances. Few have followed him on this when it comes to appeals to pity. Some textbooks leave pity out altogether. Once more, Walton's sense of things accords well with the CRM thesis. Examples discussed by Alan Brinton and Walton very plausibly seem to be legitimate arguments in which the description of piteous circumstances serve as relevant reasons for action. ${ }^{22}$ Heeding the model of the relationship between reasons and emotions put forth by the neuroscientists just noted above, the function of rhetoric is not to get the emotion of pity to overwhelm our reason and lead us slavishly and "reflexively" to act in altruistic ways. Rather, it is to call forth facts or reasons about which we should feel pity or compassion, and hence, accept as compelling reasons for action. The cogent reasoning we employ in such contexts is, therefore, 
about deciding when we are justified in action (or inaction) which harms or at least fails to benefit another person.

\section{Implicit Cogent Reasoning Pattern:}

If someone $S$ does action $A$ (which may be an "inaction") in certain circumstances, then $S$ will cause harm to (or fail to benefit) someone or something $T$.

$S$ is not morally justified in causing this harm or failing to provide this benefit to $T$.

Therefore, $S$ should not do $A$.

This is a deontic logic version of a modus tollens pattern and is what we might call a cogent practical reasoning pattern.In general and all things being equal, if my actions will cause you harm, and I have no moral justification for causing you that harm, then I should not do that action.

A fallacy is committed when the second (pivotal) premise in the implicit cogent reasoning pattern is false.For example, if a student has not been to class or done sufficient work in the course and does not have a good excuse, a professor is morally (and academically) justified in giving that student a failing grade.The traditional view about fallacies and the role played by emotions is partly correct, because the underlying hope in undeserving or inexcusable cases may be that the professor's pity for the student or guilt about causing the student harm or codependent needs to be liked by the student or other feelings will blur the professor's judgment to the extent that she does not feel justified in flunking the student. But the correct assessment is that neither the emotion of pity nor giving the student a passing grade is justified, given the falsity of the second premise.

Often, action $A$ in the cogent reasoning pattern may be inaction. Our inaction of failing to donate to a charity is what is claimed to bring harm to others. Also, occasionally this fallacy is committed by suggesting harm will occur to groups of people, animals, other living things, inanimate objects, and even abstract entities. Consider the claim that certain legislation may "bring great harm to the American First Amendment," or how much "our democracy will suffer" from certain actions. This may be only a figure of speech and require metaphoric and anthropomorphic extensions of our moral reasoning, but may nevertheless be the rhetorical ploy used in a fallacy.

The model of practical reasoning about values and actions seems to shed light on what is happening in fallacious and nonfallacious appeals to pity. In an appeal to pity, is it true or false that I am morally justified in causing someone or something harm (or failing to benefit them) through my action or inaction? That is the salient question in any pity context. Once that question is resolved, then proper reasoning from that point on is clear: simply use the cogent practical reasoning pattern given above. 


\section{Force}

Michael Wreen, Douglas Walton, and Alan Brinton have recently been flirting with accounts of the fallacy of force which come close to a CRM account. In one of his articles, Brinton says: "Professor Wreen points out that there needn't be anything logically wrong with an ad baculum, and that it need not even have questionable premises. I hasten to add that there need not be anything morally wrong either.... What really bugs us about offending ad baculums is that they are inappropriately coercive. ${ }^{.23}$ Wreen, Walton, and Brinton all seem to agree that there are nonfallacious instances of appeals to force and to entertain attempts to work out formal reasoning patterns. They are, furthermore, toying with the idea that part of the reasoning may use moral concepts. ${ }^{24}$ Also, the force fallacy traditionally is only defined in terms of threats of harm to someone who does the "wrong" thing. As the standard lobbyist example shows, however, it is often impossible to separate threats of harm from bribes or inducements. ${ }^{25}$ The lobbyist is simultaneously bribing the politician with votes and campaign contributions and threatening to take votes and contributions away, depending on how the politician votes on certain issues. Therefore, it is better to include both threats and bribes (or other inducements) in this fallacy type. However, the cogent moral reasoning patterns which are misused in this fallacy are different for threats and inducements. Putting all of these influences together:

\section{Implicit Cogent Reasoning Patterns:}

\section{Threats:}

If you do action $A$ (which may be an inaction) and $A$ is wrong, then $\mathrm{I} /$ we will be morally justified in harming you in a certain way.

You do not want to be harmed in that way.

So, you should not do action $A$.

This would seem to be a cogent deontic reasoning principle, all things being equal. Generally, if you do something wrong, then others will be morally justified in punishing you. You desire to avoid that particular punishment. So, you should avoid doing something wrong. This is structurally very close to analyses given by Wreen, except for crucial content differences. Wreen's analyses seem to take the general form:

If you do $A$, then I'll do $B$ to you.

My doing $B$ to you is an evil you would suffer.

Therefore, you should not do $A .^{26}$

The crucial difference is that the cogent reasoning pattern models the reasoning associated with morally justified retribution or punishment for wrong actions. Wreen's analyses all seem to rest on no more than prudential considerations. 
A fallacy results when the premises are false in a variety of ways. It could be the action is not wrong. Or it could be that the arguer is not morally justified in applying punishment. Or it could be that the arguee actually would not mind being harmed in that particular way. For example, voting against the lobbyist's interests may be the right, rather than the wrong, thing for the politician to do. Or the lobbyist may not have any moral justification for retributive action against the politician. Or, the politician may not fear the threatened harm--the loss of votes and contributions may not be significant enough to worry about.

\section{Inducements:}

If you don't do action $A$, then $\mathrm{I} /$ we will not be justified in rewarding (or obliged to reward) you in a certain way.

You should want me/us to be justified in rewarding (or obliged to reward) you in that way.

So, you should do action $A$.

All things being equal, this, too, is cogent. We are justified in rewarding good or desirable behavior. With threats, the type of justification was "moral," but in the case of inducements, there are many occasions where the reward and the reasons for it may not be thought moral in nature. They may be legal, economic, etc. Thus, the term "moral" has been omitted from the reasoning pattern above. For example, if I hire you to do a job for me, I am certainly obliged to pay you for your work. Frankly, most such cases seem to be "moral" as well as "legal" or "economic." Nevertheless, the term "moral" has been removed from the reasoning pattern for those with a more restrictive sense of the extension of moral concepts.

In the fallacy of bribes, both premises can be false. For example, the lobbyist is not justified (morally or otherwise) in withholding votes and contributions just because the politician didn't vote a certain way. That is, how a politician votes on an issue creates no moral, legal, economic or other obligation on anyone to reward the politician in any way, or withhold such rewards. Moreover, perhaps the politician should not want to be the recipient of the lobbyist's favors, so even the second premise might be false.

Many discussions of the fallacy of force include examples in which someone is wamed about impersonal threatening circumstances. ('Look out, or you'll be run over by that truck!") ${ }^{27}$ These are not what I take to be paradigm cases of the force fallacy. There must be something personal and direct about the threats or bribes offered in the force fallacy, which is why the cogent reasoning patterns are structured with first and second person pronouns. Appeal to impersonal fears will be dealt with under the ad hominem circumstantial fallacy category.

A general problem with the CRM account is making a convincing case that so much complex structure could be implicit in examples which are on the surface quite simple. Perhaps the reader has been content up until now to wait for the promised justification in Section III, but may be feeling at this point that the fallacy 
of force analysis definitely goes too far. "Really now! We're to construe the remarks of bullies and muggers as hiding implicit complex moral reasoning? Come on!" The situation is even worse than that: informal logicians have frequently puzzled over how this fallacy can really be a fallacy at all. How can threatening someone be seen as involving any kind of mistake in logic? The solution to this puzzle lies in recognizing that most people who give threats don't conceive of their action as an unjustified appeal to force. Rather, they see it as a warning of deserved punishment or justified retribution for misbehavior. For example, one excellent recent example of threats of force was a series of statements made by Saddam Hussein just before the invasion of Kuwait. While many statements were loaded with threats, other statements also clearly indicated that Hussein felt totally justified in taking forceful action against Kuwait. Kuwait was simply going to "get what it deserved" because of its history of perceived betrayals of Iraq. Psychological models of anger and such phenomena as "road rage" suggest that people who threaten or actually use force usually feel the same way, at least in the heat of the moment. From their point of view, they are not threatening for purposes of evil gain or satisfaction, but warning that there will be moral retribution because of adequate provocation, such as injustice, insults, or other injuries. ${ }^{28}$ Interviews with spousal-batterers reveal that the batterer and sometimes even the victim(!) feel the beating was justified. ${ }^{29}$ Thus, it is not that far-fetched to suggest that the reasoning paradigms associated with threats of violence or harm is justified punishment or justified retribution. A fallacy is committed when people are morally confused, when they are led to false judgments about what constitutes proper justification, or the appropriateness of (perhaps violent) punishment in the given circumstances.

Douglas Walton poses a tough case in his example of a mugger who robs someone at gunpoint. ${ }^{30} \mathrm{He}$ attempts to supply what he calls "prudential arguments" to explain the fallacy in such threats. Critics of Woods and Walton have reacted strongly to their treatment of the force or ad baculum fallacy, and have found the mugger example implausible, especially if there is any suggestion that the victim is also in some way committing the fallacy. In answer, it needs to be first observed that the muggee in this case may not be committing a fallacy at all. The muggee may be very prudentially and nonfallaciously handing over the wallet or purse. Not everyone who encounters a fallacy necessarily falls prey to it. But second, the mugger may very well be committing exactly the fallacy as described. Violent and criminal behavior may often be rationalized by perpetrators as something they have a right to do, given past experiences or social injustices visited upon them. They may not be especially conscious or articulate about these implicit justifications, but such a Platonic moral conception ("no one knowingly does wrong") may well be applicable to such cases. We need to take seriously the moral psychology of individuals utilizing threats of serious violence. However irrational, unreasonable, illogical, and immoral violence may seem to us, we must acknowledge that in the "moral" worldview of many, violence is to be expected and is an ac- 
cepted means of resolving disputes. Their behavior is best seen, not as the result of bad reasoning or invalid thinking, but as the result of an unfortunate false view of how life is. Thus, even Walton's extreme case of the mugger seems to fit the model of the force fallacy outlined above.

\section{Ad Hominem Circumstantial}

Alan Brinton defines the ad hominem circumstantial fallacy as "attempting to show that, given certain alleged facts about one's opponent's background, behavior, prior commitments, or other circumstances, it is inconsistent for that opponent to accept (or reject) a particular point of view." ${ }^{31}$ Reshaping this slightly to conform to the CRM account, we get the following:

\section{Implicit Cogent Reasoning Patterns:}

(1) If you believe or do A, then you will be inconsistent in a certain way. You shouldn't be inconsistent in that way.

Therefore, you should not believe or do A.

(2) If you do not believe or do A, then you will be inconsistent in a certain way.

You shouldn't be inconsistent in that way.

Therefore, you should believe or do A.

In this reasoning pattern there is an alleged inconsistency between a person's circumstances and opinions or actions. Strictly, inconsistency can be applied only to statements, but I will extend the notion here to include inconsistency between words and actions, such as when someone does not "practice what is preached." The reasoning can be used either to question or reject expressed views (1) because of an inconsistency with past or present circumstances; or (2) to urge acceptance of a point of view in order to remain consistent with past or present circumstances. In this latter form, the pattern is a catch-all for other emotional appeal fallacies. Appeals to loyalty ("Any loyal union member will support the strike!") or to fears ("Do you want an America where you can walk the streets safe at night? Support the National Rifle Association!") are two of the most common appeals of this sort. Others include pride, shame, anger and guilt, such as one might hear from a coach to a losing team. This is a cogent practical reasoning pattern. We abhor inconsistency in thought and action because it indicates either logical incompetence or hypocrisy. Therefore, if someone is genuinely inconsistent, then beliefs or behavior responsible for the inconsistency must be changed.

Consistent with the CRM thesis, a fallacy is brought about by falsity in one or both of the premises. The belief or action may simply not imply the indicated inconsistency, or since what is being pointed to as inconsistency is not genuine, perhaps you should be "inconsistent" in that way. For example, not supporting the strike may not be inconsistent with loyalty to one's union (false first premise) or 
there may be good reasons why you should not be loyal to the union (i.e., why you should be inconsistent with your loyalty to the union) in the current circumstances (false second premise).

\section{Informal Fallacies-Gricean Premises}

For this next category of fallacies, we will look at cases in which one of the premises within the implicit reasoning pattern has a "metalinguistic" status. The role it plays in the implicit cogent reasoning is similar to the role played by "conversational rules" as enunciated by H. P. Grice. Robert Fogelin provides an excellent explanation of H. P. Grice's "conversational rules" and how they function in "conversational implications." We follow Grice's conventions routinely in our conversations but also "(1) implicitly realize that we are following them, and (2) expect others to assume that we are following them. This mutual understanding of the commitments involved in a conversational act leads to the following important result: people are able to convey a great deal of information without actually saying it." ${ }^{\prime 2} \mathrm{n}$ addition, "Sometimes our speech acts seem to violate certain conventions. On the assumption that the conversation is good-willed and cooperative, the listener will then attempt to make sense of this in a way that will explain why the speaker is transparently violating a conversational rule." ${ }^{33}$ To add such metalinguistic premises to the cogent pragmatic reasoning schemas places an extra burden on the CRM account. However, the fact that Gricean implication models have been adopted by researchers in cognition and communication ${ }^{34}$ suggests that such models retain an empirical character.

\section{Begging the Question}

Douglas Walton introduces the concept of "evidential priority" in order to explain circular reasoning or the begging the question fallacy. Evidential priority means "that the premises are being used as evidence to support the conclusion in such a way that each premise must be capable of being established without having to depend on the prior establishment of the conclusion, in the supporting line of argumentation backing up the premise." 35 his is an eloquent and precise way to express a general expectation, of a Gricean sort, which seems to be violated when we confront fallacious circular reasoning. Borrowing Walton's formulation:

\section{Implicit Cogent Reasoning Pattern:}

A.

Premise $A$ has evidential priority with respect to Conclusion $B$.

So, $B$.

This seems obviously cogent. If $A$ is a good reason to accept the truth of $B$, and $A$ is true, then clearly we have a good reason to accept $B$. But in order for $A$ to serve as a "good reason" for $B$, it must have evidential priority in Walton's 
sense. The fallacy in many examples of begging the question is that the second metalinguistic premise is false. Walton's evidential priority criterion seems to come closest to Grice's first "Quantity" principle: "Make your contribution as informative as is required (for the current purposes of the exchange)." ${ }^{36}$ In typical begging the question fallacies, some important information has been suppressed, namely, that the premises lack the requisite evidential priority. While it may be an added complication to include such metalinguistic premises in the CRM thesis, if Grice and others are correct, such premises often play a role in our inferences. It is not too great a leap to suppose that pragmatic reasoning schemas of the Nisbett type may also involve such "meta-premises."

\section{Equivocation}

In his classic treatment of fallacies, C.L. Hamblin laments the absence of good examples of equivocation. Quoting some humorous Elizabethan poems (which are basically riddles), he says, " . . . whatever our feelings about maids in Camberwell or the Mayor of Erith, we are hardly capable of being deceived by any serious chain of reasoning exploiting the double-meanings in the statements about them." ${ }^{37}$ The situation has hardly improved. Lawrence H. Powers article "Equivocation" is filled with the same sorts of examples Hamblin decries, such as the old standby "This dog is a father and this dog is mine, so, this dog is my father." ${ }^{.38}$ So, are there no authentic examples of equivocation which actually fool people through the manipulations of meanings in an argument? Here's one, from an investment company's advertising brochure, which is effective and at least regularly fools students in my classes:

The primary difference between what we do and what most other investors do is that we make Tactical Asset Allocation decisions based upon a quantitative, systematic, disciplined modeling process and most other investors make these decisions on a subjective, emotional and/or random basis. This is a fatal error, because most investors, left to their own devices, are emotionally out of sync with the markets. ${ }^{39}$

The equivocation is on the phrase "most other investors." Students regularly think the passage is referring to "most other investment companies." In fact, the passage is merely comparing the company with private individual investors. Failing to note this equivocation makes the company look quite good in comparison with its competitors.

Other authentic examples of equivocation are the "all-some" equivocations often occurring in commercials and political speeches, in which an unquantified statement such as "Doctors recommend X more than any other brand" switches its implicit quantification from "all" to "some." The effect is to make the statement seem true under the "some" interpretation, and to make the argument seem cogent under the "all" interpretation. What creates the fallacy in these cases is the violation of another Gricean-type metalinguistic premise. Grice actually gives as the second maxim of "Manner" that we should "avoid ambiguity." Certainly, we tend 
to assume the consistent, unequivocal use of language in arguments, what Hamblin calls "meaning-constancy." 41 Meaning-constancy, however, must be defined as something more than just the consistent use of language. When we accept this meaning-constancy premise on a given occasion, we are assuming that the truth of the premises is compatible with the meanings of concepts remaining constant throughout the whole set of premises. That is, it is not necessary to change the meanings of concepts across the premises in order to preserve the truth of the premises. However, meaning-constancy is also a prerequisite of the cogency of the reasoning. Thus, the meaning-constancy premise insists that the cogency of the reasoning is compatible with the soundness of the reasoning. Equivocation destroys that compatibility.

\section{Implicit Cogent Reasoning Pattern:}

$P, P^{\prime}, P^{\prime \prime} \ldots$
If $P, P^{\prime}, P^{\prime \prime} \ldots$ then (probably) $C$.
The premises $P, P^{\prime}, P^{\prime \prime}, \ldots$ possess meaning-constancy.
So, (probably) $C$.

In our example, the meaning-constancy premise is false because in order to preserve the truth of the other premises, the meaning of "most other investors" must change. But if the premises $\mathrm{P}, \mathrm{P}$ ', $\mathrm{P}$ '... are assumed to have meaning-constancy, then they provide good reasons to accept $\mathrm{C}$. In the pattern, the term "probably" is inserted parenthetically, because the reasoning may be either deductive or inductive. Incidentally, the lack of meaning-constancy is also why it is insufficient to explain the fallacy simply by identifying the equivocation. What is wrong with equivocating, why should we see it as a fallacy, especially if most standard examples of it are transparent bad jokes? The answer is that to really explain what is fallacious about equivocating, we need to understand the effect it has on the cogency and soundness of reasoning in serious examples. That is, we need to understand that it creates an incompatibility between cogency and soundness. But that is simply to say that the metalinguistic meaning-constancy premise is false.

So many of the textbook examples of equivocation seem like bad jokes, that perhaps we ought to wonder if there isn't a reason. In fact, I think there is. According to Grice, when we obviously and overtly violate a conversational rule, our audience will attempt to make sense of that. When we obviously violate the rule of meaning-constancy, it has a punning or riddling quality about it, which will most likely lead to the implication that we are trying to say something funny and are not attempting to deceive or manipulate anyone. Thus, these are not poor examples of the fallacy of equivocation--they are not examples of that fallacy at all. They may be violations of the meaning-constancy premise and thus, unsound inferences, but they fail to satisfy the third feature of the CRM definition of fallacies: there is no culpable ignorance or deception involved. This will be explained further in Section IV. below. Not unexpectedly, there is nothing obvious (or humorous) about successful and fallacious violations of meaning-constancy. 


\section{E. Informal Fallacy-Analogical Reasoning}

\section{Questionable Analogy}

Correct reasoning by analogy is another form of inductive reasoning. Often this fallacy is not classified as a type of informal fallacy, but as a type of statistical or inductive fallacy. It is included here because the nature of the fallacy is roughly the same as the other informal fallacies: misusing a cogent pattern of reasoning by having a false premise. Moreover, it is a fallacy commonly occurring outside of what we might think of as "statistical" contexts.

\section{Implicit Cogent Reasoning Pattern:}

Case $A$ is like Case $\mathrm{B}(C, D$, etc. $)$ in having the same relevant characteristics, $c_{1}, c_{2}, c_{3}, \ldots$

Case $B(C, D$, etc. $)$ also has characteristic $x$.

So, Case $A$ probably has characteristic $x$.

Consider this example: "One of the first things the Nazis did when Hitler came to power was to initiate gun control. Guns were taken away from all German citizens. So, we can be assured that if the gun control advocates have their way, a new fascism will reign in America." So, why is this analogy a fallacy? Because there are very few relevant similarities between the U.S. today and Nazi Germany in the 30 's, and very many relevant dissimilarities. Thus, it would be unreasonable to expect the same results if gun control were enacted in the U.S. Notice, significantly for CRM, that it is again a false premise within a cogent reasoning pattern which produces the fallacy.

Trudy Govier classifies such fallacies as a priori analogies. ${ }^{42}$ In her excellent discussion, she rejects various attempts to include further implicit premises, such as a "universal claim" in order to provide a "deductivist reconstruction." This would amount to including, for example, the following premise in the above cogent reasoning pattern: "All things which have $c_{l}, c_{2}, c_{3}, \ldots$ also have $x$." Among other problems this creates, it destroys the analogical reasoning: the conclusion follows from just the fact that $A$ has the characteristics together with the new premise. The comparison with cases $B, C, D$, etc., becomes useless. Thus, it seems best to view analogical reasoning as the very simple inductive pattern given above, which remains consistent with the CRM thesis. It is notoriously difficult to specify what constitutes "relevant" differences and similarities, but analogical thinking seems to play an important, and frequently nonfallacious, role in ordinary inductive reasoning, and that is all CRM requires.

\section{F. Informal Fallacies-Miscellaneous Others}

\section{Composition and Division}

In the fallacies of Composition and Division there seems to be some kind of shifting between the distributive and collective meanings of terms in an inference, or 
the misuse of property terms "sensitive" to part-whole shifts. To cite a classic example common in the literature:

All the parts of this machine are light. Therefore, this machine is light.

\section{Implicit Cogent Reasoning Patterns:}

\section{Composition:}

(1) All the parts of $X$ are $A$.

(2) $\mathrm{A}$ is the kind of property for which if all the parts of some collection or whole $X$ have property $A$, then $X$ will have property $A$.

(3) So, $X$ is $A$.

\section{Division:}

(1) $X$ is $A$,

(2) $A$ is the kind of property for which if some collection or whole $X$ has property $A$, then all the parts of $X$ will have property $A$.

(3) So, all the parts of $X$ are $A$.

There are nonfallacious cases: substitute the phrase "made of iron" for the word "light" in the example and you have one such case. Thus, the problem is to determine in the second premise whether $A$ is or is not the sort of property sensitive to distributive/collective or part/whole changes. Not always an easy task, but as far as the CRM thesis goes, this analysis does seem to explain the fallacy. There seems to be a fairly good correspondence between cases of fallacy and cases in which the second premise is clearly false.

This is a good fallacy with which to illustrate another aspect of the CRM thesis: fallacious cases are parasitic upon nonfallacious uses. The nonfallacious uses establish trust in the cogent reasoning pattem and lead to a habitual application when the correct "prompts" are given. Nisbett's research supports this (see n. 5 above): there is some kind of "induction," according to Nisbett, of the cogent pragmatic reasoning schemas from everyday experience. For the composition and division fallacies, we can imagine that this induction occurs with the wealth of common properties for which composition and division inferences are sound. The fallacies, then, are lapses of sophistication, when one gives way to the tug of ingrained reasoning habits while oblivious to their inappropriateness (falseness) in a given case in which the properties are sensitive to distributive/collective or part/ whole changes.

\section{Complex Question}

This is the fallacy of asking a "loaded" question in hopes that some presupposition of the question might be accepted as true. This may also involve some manipulation of the situation, such as badgering or interrupting, to help the fallacious inference along For example, in the film $A$ Time to Kill, while outside the courtroom 
the assistant to the defense attorney asks one of the prosecuting attorneys: "How are you coming along with that impotency problem?" (Asked of someone who does not obviously have an impotency problem.) The person to whom the question is addressed is shocked and does not respond.

\section{Implicit Cogent Reasoning Pattern:}

(1) All presuppositions of a question are true if it can be properly answered simply "yes or no."

(2) The question was asked and can receive a proper simple answer (and any failure by the respondent to answer simply and quickly is the result of evasiveness, etc.)

(3) Hence, a particular presupposition of the question is true.

In this case, a "yes or no" answer, or failure to answer quickly enough through confusion or interruptions, etc., results in the fallacy. The CRM thesis is preserved because it is false that the question, being complex, could be answered properly (even if, through confusion, it was answered simply). Part of the point of calling this the fallacy of "complex" question is to call attention to what has been missed by anyone committing the fallacy: no simple "yes or no" answer is proper. Note well, however, that the fallacy results from premise (2) being false, not the "Gricean" premise (1).

This completes the task of giving an implicit cogent reasoning analysis for a sample of traditional informal fallacies. It is now time to consider other issues raised by the CRM thesis.

\section{Problems and Justifications}

The role of "implicit" reasoning bears a heavy load in this account of informal fallacies. The CRM account requires that we import a lot of complex implicit reasoning structures into arguments which are very simple on the surface and seem to be merely fallacies of irrelevance. Why should we believe such complex reconstructions are appropriate analyses rather than mere ad hoc impositions of structure?

\section{Considerations of the Principle of Charity}

The questions which head this section point to the general problem of reconstructing enthymematic arguments. Troubles with the problem of enthymemes begin with even stating what the problem is. Sometimes, the problem is described as the problem of recovering "missing" or "hidden" premises. But a self-contradiction lurks, as David Hitchcock points out. Whether we call the premises "missing," "hidden," "unexpressed," "tacit," "unstated," or "suppressed," "we seem to be saying that an argument has a premiss which it does not have." problems multiply quickly when we begin to think about reconstructing and evalu- 
ating enthymematic arguments. In the same issue of the journal as Hitchcock's article is an excellent treatment of the subject by Michael Burke. ${ }^{44}$ Burke critically discusses the accounts of Ennis, Hitchcock, Schwartz, and Scriven and finally offers his own. At the beginning of Burke's article, he presents two "uncontroversial criteria," which he says all four authors hold in common. They are:

\section{The sufficiency requirement:}

"The unstated premises must be sufficient to validate, or at least to strengthen, the inference."

\section{The preservation requirement:}

"We should try to preserve the role of the stated premises ... we will not want to add propositions that would nullify their contribution to the strength of the inference." ${ }^{\text {45 }}$

Burke is isolating for us the least controversial parts of what many have struggled to identify as a principle of charity: Do not evaluate enthymematic arguments in terms of their mere explicit structure. Rather, be generous and charitable in seeking underlying premises or assumptions which validate or strengthen the inference. But also, in doing so, be faithful to the explicit statements the author has presented. But while there is fair consensus about applying this policy to enthymematic arguments, a curious thing has happened in the field of informal logic. If the topic is the identification and discussion of informal fallacies, the principle of charity is set aside. ${ }^{46}$ And this compartmentalization of informal fallacies in one place and enthymematic arguments in another place appears endemic in informal logic. This is, literally, to guarantee an uncharitable stance toward any argument which might be fallacious. The argument doesn't actually need to be fallacious; it just needs to be unlucky enough to be selected for evaluation at a time when the informal logician has donned fallacy-detector goggles and can see the world through no other lenses.

The truth is, however, that arguments and claims do not come pre-identified as "This is an informal fallacy-determine which one!" or "This is not an informal fallacy, but an enthymeme-be charitable!" And so there seems to be no principled reason for the prejudicial policy of not treating what is possibly an informal fallacy as an enthymematic argument. One significant virtue of the CRM account is that it requires charitable reconstructions of the good reasoning being used in informal fallacies. Furthermore, the general justification for applying the principle of charity to any argument is that, besides being fair, it produces stronger, better criticisms of an argument by identifying false or implausible implicit premises. This is also true of the CRM account--the reconstructions help expose the false premises responsible for the fallacy. Informal fallacy analysis, on the CRM account, actually becomes a mere extension of critical thinking approaches to enthymematic arguments. 
Why have informal logicians believed that they should exclude informal fallacies from consideration as enthymematic arguments? One might surmise that past approaches to informal fallacies may have been prejudiced by tradition, beginning with Aristotle. After all, if these are "fallacies," then how could they involve cogent reasoning? Thus, it would be pointless to look for what obviously can't be there. Taking a stand against this common prejudice, there does not appear to be any good reason why we should exclude informal fallacy cases from application of the principle of charity. Indeed, if we accept the principle of charity, then we are enjoined to do so-the absence of a reason disqualifying the argument from application of the principle, compels its application. However, if real cases of informal fallacies are to be "charitably reconstructed," this places a burden of proof on the reconstructor, following the principle of charity, to reconstruct them as valid or cogent, or provide substantial explicit evidence that this should not be done for a specific case (e.g., on other grounds it can be argued that the reasoning pattern is invalid). That being so, the burden of proof descends on informal logicians to either supply such reconstructions or to supply good evidence in any particular example of an informal fallacy that the reasoning employed is not cogent.

The conclusion so far is still fairly weak and does not provide much support for the specific CRM account given in this paper. The conclusion runs: "If one accepts even the uncontroversial elements of the principle of charity given by Burke, then, absent a contrary reason which justifies alternative treatment, one must treat informal fallacy examples as enthymemes and attempt to reconstruct them as cases of cogent reasoning." This, of course, requires only that we tryit doesn't guarantee success. Nor does it provide any support for the specific analyses given above for each fallacy type. But actually, I'm content with that much. I' $m$ prepared to be shown that most or all of my attempted reconstructions are incorrect and erroneous, and that better ones exist. Or that there are numerous examples requiring variant reconstructions within clusters of a fallacy category. My reconstructions represent only an initial attempt to show that the project could be carried out at all, with even a minimal degree of plausibility. Continuing to exclude informal fallacies from charitable treatment, however, would be to perpetuate arbitrariness, and I'm urging the informal logic community to reconsider this policy. Traditionally, those writing about fallacies have frequently raised questions about particular fallacies, noting that it seems in many cases that this particular fallacy may in some contexts actually not be fallacious. Woods and Walton deserve much credit for recognizing that such questioning needs to be done systematically across the entire spectrum of informal fallacies, and fortunately, a few others such as Brinton and Wreen have followed their lead. I am arguing that it is time for informal logicians to go one step further, and to recognize that the principle of charity requires not just a systematic recognition of nonfallacious examples, but a concerted effort to reconstruct the cogent reasoning underlying informal fallacies. This means acceptance of the CRM thesis in general form if not in the specific content I've provided. 
Thus, my first answer to the questions which head this section is that acceptance of even the minimal and uncontroversial elements of a principle of charity require us to seek cogent reasoning structures in informal fallacy cases. The burden of proof is on those who resist such attempts but who otherwise assent to the principle of charity to show why informal fallacies should be excluded from the category of enthymemes. ${ }^{47}$

\section{Empirical Evidence for CRM}

CRM is a speculative hypothesis about what kinds of reasoning patterns people employ in making inferences traditionally labelled "informal fallacies." CRM claims that there are actual cogent reasoning patterns which are really used by people when committing fallacies. This has clear empirical implications, and as such, is subject to empirical testing.

At present there is no "direct" empirical evidence to support the CRM hypothesis. There is, however, a considerable body of evidence to support the existence of abstract reasoning rules similar to those proposed by CRM. The work of Nisbett and colleagues (cited earlier) is of great significance to informal logicians. Using variations of the Wason selection task ${ }^{48}$, they have assembled an impressive body of findings which show that subjects are just as likely as the control group to commit formal fallacies (affirming the consequent and denying the antecedent) after a brief training session on the conditional, and even after an entire semester's course in formal logic. However, when presented with conditional problems logically equivalent to the formal abstract rules, but which evoke concepts of permission or obligation, the subjects' performance improves dramatically, even without training. Subjects in these cases are presented with conditional sentences like, "If a passenger wishes to enter the country, then he or she must have had an inoculation against cholera." Brief training on the obligation schema resulted in even greater improvements in performance. ${ }^{49}$

Nisbett and several of his colleagues (Patricia W. Cheng, Keith J. Holyoak, and Lindsay M. Oliver) argue that

pragmatic reasoning schemas guide much of people's everyday deduction. These researchers examined the Wason problems with everyday content on which subjects performed particularly well and noticed that the rules involved relationships of permission, obligation, and causation. They argued that the high performance on these problems comes not from a familiarity with the content domain but rather a familiarity with domain-independent pragmatic schemas. These schemas are structured around relationships of practical relevance to social and physical problem solving. Although pragmatic schemas can be applied across content domains, they are restricted in application to certain qualities of relationship (e.g., permission) between certain kinds of entities (e.g., actions). Proponents of the schema view of deduction grant that content knowledge may influence reasoning in familiar domains and that people may use propositional rules when no schema can be applied ..., but maintain that for problems interpretable in terms of pragmatic 
schemas, deduction is primarily schema-based. Moreover, proponents claim that training in the use of schemas or training in academic disciplines based on the schemas improves deduction whereas training in formal, propositional rules does not . ... 50

In saying that the evidence for the CRM hypothesis is indirect rather than direct, I mean simply that the Wason selection test is not designed to reveal anything about the specific nature of reasoning occurring within any of the informal fallacies. Nevertheless, the evidence is strong that pragmatic reasoning schemas apply to "relationships of practical relevance" such as the contractual relations of permission and obligation, causality, and economic relations. In addition, fairly sophisticated schemas exist for statistical reasoning, such as using the law of large numbers (small sample). These pragmatic schemas all exist "naturally," but their employment is enhanced by training. Furthermore, a point not stressed by Nisbett and his fellow researchers because of their "descriptive" rather than "normative" orientation, the pragmatic schemas are cogent: deductively valid or inductively strong. Hence, there is considerable evidence that natural modes of both deductive and inductive cogent reasoning exist which apply across a wide range of social and physical domains. Needless to say, these domains cut across a number of the domains where we find informal fallacies committed, and thus there is substantial indirect evidence that these pragmatic reasoning schemas may indeed underlie "fallacious" reasoning.

It could be argued that the speculative CRM hypothesis should not be publicly proposed until some direct evidence is obtained, until, for example, a suitable variation of a Wason selection test is designed and administered on cases which test reasoning for instances of authority-based reasoning, false dilemma reasoning, etc. To argue this would be to impose an unusually high standard of evidence on a philosopher. But in part, to seek such evidence is outside my territory, and perhaps, if the hypothesis survives the "normative" deliberations of philosophers, it may attract the "descriptive" testings of cognitive scientists.

It bears emphasizing that this is a philosophical thesis. Though I've characterized it as a speculative hypothesis with empirical consequences, it is nonetheless essentially a philosophical work within the growing informal logic tradition of reconstructions of informal fallacies. Walton and others may depart from the CRM account in significant ways, but as we have seen, there is increasing reliance on philosophical intuitions to make sense of the kind of reasoning to be found in fallacies. Consensus on our intuitions may not be as compelling as empirical evidence (at least to some), but it is still something worth seeking, certainly during the formative and speculative phase of a theory's development.

One last point in favor of CRM: Nisbett's research reveals an important contrast between the ability of people to deal with highly abstract cases based on standard formal logic and test cases based on pragmatic reasoning in everyday life. Performance dramatically improves with the latter. David Hitchcock reports on an experience familiar to many of us: 
Almost two decades ago, at the end of a course in introductory symbolic logic, I turned to a section of the text that dealt with informal fallacies. The students' interest immediately rose. Here were passages of prose recognizably like the things they were used to hearing and reading, and it was great fun to label the commonly made mistakes. Unlike the meaningless letters and novel symbols of the propositional and first-order predicate calculus, these exercises had obvious application to everyday life. ${ }^{51}$

Could it be that the typically greater student appreciation of the topic of informal fallacies compared with other things we teach in informal logic courses results from something deeper than mere familiarity? Could it be that here at last is some reasoning they can really understand?

\section{Further Support for CRM}

Beyond empirical support, we can point to a number of virtues of the CRM account:

First, CRM greatly unifies the subject. If true, CRM would provide a significant advance in developing a systematic, coherent, and simplified theory of fallacies. Moreover, as the Nisbett research indicates, there are likely to be major pedagogical benefits as well.

Second, a constant theme in Walton's work has been the existence of both fallacious and nonfallacious instances of each type of fallacy. Walton has demonstrated this by assembling a persuasive body of arguments and examples. CRM simply and neatly explains this property of informal fallacies; in fact, we get that explanation for free-it falls right out of the CRM analysis. This feature of fallacies is sometimes noted as another indication of the hopeless messiness of the subject. Instead, it seems to be what the CRM account of fallacies predicts must come with the territory. And anyway, some degree of messiness coheres better with basic principles of good critical thinking. The days of thinking we can easily resolve a dispute by placing a fallacy label on someone's argument should be behind us by now. Nevertheless, if a correct account of informal fallacies, CRM would provide good focus for dispute resolution: it tells us to examine the truth or falsity of the explicit and implicit premises within a clear reasoning structure. Arguing the truth or falsity of the premises will itself often be messy, but it need not be. Sometimes it will be relatively easy after reflection to obtain recognition of or agreement about the falsity of the premises once they are made explicit. Hopefully, this will even happen with sufficient frequency to make it worth teaching about the informal fallacies.

Third, relevance problems almost evaporate. There is no need to provide a general theory of relevance or work out relevance criteria for numerous fallacy types. Only the authority, ad hominem abusive, and questionable analogy fallacies raise relevance concerns in the CRM account. Moreover, these concerns are quite specific, relating to criteria for judging one of the premises true or false, and restricted to determining the relevance of various personal characteristics for tes- 
timonial credibility and reliability, and determining which are the relevant analogical properties.

Fourth, CRM permits a more precise and accurate classification of fallacies. Determining whether or not a certain pattern of cogent reasoning is a plausible reconstruction of a claim provides independent grounds for category assignments. (Recall the above suggested reclassification of one of Wreen's examples as ad hominem circumstantial rather than force.) CRM even permits cross-classifications of examples as multiple fallacies, but in a way that clarifies rather than befuddles. (Recall the above discussion of examples which seem to overlap false dilemma and slippery slope.) What Gerald Massey calls an "exaggerated fascination with taxonomies" is truly a sin to be avoided. ${ }^{52}$ But that an account allows for more perspicuous and independently-grounded taxonomizing surely remains a virtue.

\section{Solving the Demarcation Problem--the Role of Pivotal Premises}

A further serious problem needs to be addressed. How should we distinguish an example of a fallacy from an example of unsound but nonfallacious reasoning, when both use the same cogent pattern? For example,

A. Fallacy:

Either vote for Jones, or your taxes will go sky high next year. [You don't want your taxes to go sky high next year.] [So, vote for Jones]

B. Unsound and possibly nonfallacious:

When we get to the ice cream place, I'm going to have either a Banana Crunch or a Chocolate Fudge, double scoop on a sugar cone... Well, here we are. Oh no! The sign on the display counter says they are out of Banana Crunch!. Well, that's all right. I'll just have the Chocolate Fudge. (unbeknowst to the customer, they also just ran out of Chocolate Fudge, so the first premise is false.)

C. Unsound and very plausibly nonfallacious:

Either we should get a station wagon, or a larger vehicle like a van, sport utility vehicle, or even a pickup. But according to the literature I checked, I don't think a station wagon will be big enough to haul the people and stuff around we need to. So, I guess we need to get one of the larger vehicles--a van or something else. (Suppose in this case that information is not readily available about one larger specialty model of station wagon which would provide ample room to meet the speaker's hauling concerns. Thus, suppose that only the second premise in this example is false.)

Even though all three examples share the same false dilemma cogent reasoning structure, and all three have one false premise, I am disinclined to call Example B a fallacy, and quite reluctant to call Example $\mathrm{C}$ a fallacy. Example $\mathrm{B}$ may be a mistake or error of some kind, but doesn't seem to engage in the rhetorical vi- 
ciousness we associate with paradigm cases of fallacy. And Example $\mathrm{C}$ appears to be a quite innocent error leading to unsound reasoning, but not meriting the fallacy title. These examples imply the existence of a general demarcation problem for the CRM account. There is no apparent reason why such nonfallacious but unsound examples cannot be generated or found for most or all of the fallacies analyzed above.

The solution to the demarcation problem is to note, first, that many of the fallacy accounts above focus on the falsity of the "pivotal" premise when a fallacy occurs. So, in cases where the pivotal premise is not the one which is false, then perhaps there is room for nonfallacious unsoundness. This would seem to explain Example $C$. This answer is unsatisfactory, however, for a couple of reasons. It does not explain our uneasiness about calling Example B a fallacy. Of course, intuitions may differ about this, and someone may be inclined to tough it out and say, surely Example B and any other case in which the pivotal premise is false is a fallacy: in this example, the customer needs to broaden her tastes a bit and sample the many alternatives to Banana Crunch and Chocolate Fudge. My intuitions go the other way on this example-calling this a fallacy seems incorrect. Regardless, the further problem is that no general account of what it means to be a "pivotal" premise has yet been given. Why should we identify certain premises as "pivotal," what is it about them that gives them such a special role?

So, as a second solution to the demarcation problem, consider the following. If the CRM account is right, then fallacies occur when the cogent pragmatic reasoning schemas get misapplied and falsity creeps into the premises. If this occurs primarily in social contexts, then some element of responsibility or culpability for propounding or accepting false premises may be involved. That is, the demarcation problem is to be solved by determining whether or not there is some degree of innocence or guilt associated with the assumption, assertion or acceptance of the false premises. Are the false premises presented or accepted as true because of ignorance which is innocent and perhaps due to circumstances beyond the control of the reasoner? (Example C, and possibly Example B) Or are the premises false as a result of deception, manipulation, sleazy trickery, rhetorical extremism, distortion, sophistry, and varieties of self-deception, carelessness and gullibility in which the falsity (or promoting, or taking advantage of the falsity) is culpable and offensive? This distinction seems intuitively to cut the fallacy/nonfallacy cases at the joints in the right way. Thus, pivotal premises are those which regularly and commonly are the locus of culpable and offensive deception or ignorance. And the demarcation problem is solved by noting that informal fallacies involve some degree of culpable deception or ignorance associated with the false premises, whereas nonfallacious-but-unsound cases do not. ${ }^{53}$

The demarcation problem and recognition of the role pivotal premises play in most of the fallacies provides the reason for addition of the third feature in the definition of informal fallacies with which this paper began. It needs to be clarified that the absence of designated pivotal premises in some of the analyses above only 
signifies that culpable ignorance or deception will often occur with all or more than one of the premises. Most of the emphasis in this paper has been on the first two features, because I perceive these as the most controversial in comparison with alternative theories of informal fallacy. Nevertheless, my intuition about informal fallacies has always been that they are usually connected with culpable deception and ignorance, and it is important to end this account with some indication that the CRM thesis can readily accommodate this important normative feature. A more elaborate examination of this third feature, however, must be deferred to another occasion, since this account is already too long.

\section{Work In Progress}

Obvious areas of future work on the CRM account include:

1. Seeking direct empirical evidence that cogent pragmatic reasoning schemas underlie fallacy instances.

2. Refining the present fallacy accounts through improved philosophical reconstructions in the face of future criticisms.

3. Extending the CRM analysis to additional fallacies historically identified and classified.

4. Comparing the CRM account with the pragma-dialectical approach of Frans H. Van Eemeren and Rob Grootendorst, the rhetorical approach of Charles Arthur Willard, the argumentation schemes approach of Douglas N. Walton, and other alternative accounts of informal fallacies. ${ }^{54}$

5. Elaborating further the third feature in the CRM definition of informal fallacies: the association of degrees of culpable ignorance or deception with the falsity of the premises.

I believe that the present paper launches the CRM account with sufficient detail to stimulate serious discussion and criticism and lays the foundation for these areas of future effort. ${ }^{\text {ss }}$

\section{Notes}

'See, for example, Douglas N. Walton, Informal Logic; A Handbook for Critical Argumentation (Cambridge: Cambridge University Press, 1989), Only a few of the informal fallacies are analyzed as "argumentation schemes," e.g., p. 192 and p. 257 . However, Walton goes much further in Argumentation Schemes for Presumptive Reasoning (Mahwah, New Jersey: Lawrence Erlbaum Associates, Publishers, 1996). In that work, Walton provides argumentation schemes for many types of fallacy. However, Walton wants to classify fallacies not in terms of the unsoundness of argumentation schemes but in terms of the violation of goals of dialogue. Most of Michael Wreen's work has been on the ad baculum fallacy.

${ }^{2}$ Richard E. Nisbett (ed.), (Hillsdale, New Jersey: Lawrence Erlbaum Associates, Publishers, 1993), p. 7.

${ }^{3}$ Ibid., p. 186. 
${ }^{4}$ Indeed, many of the rules investigated by Nisbett and others are statistical rules.

${ }^{5}$ Nisbett, op. cit., p. 192.

${ }^{6}$ Credit for this suggestion goes to Jonathan Adler.

${ }^{7}$ Robert James Bidinotto, "Crime and Consequences," The Freeman, July and September, 1989. Reprinted in Violence in America (San Diego, CA: Greenhaven Press, 1990), pp. 268-270.

${ }^{8}$ Ronald Otremba, "Is Active Euthanasia Justifiable?" Active Euthanasia, Religion, and the Public Debate, 1991, reprinted in Euthanasia (San Diego, CA: Greenhaven Press, 1995), p. 23.

'See, for example, David Hitchcock, "Do the Fallacies Have a Place in the Teaching of Reasoning Skills or Critical Thinking?" in Hans V. Hansen and Robert C. Pinto (eds.), Fallacies: Classical and Contemporary Readings (University Park: The Pennsylvania State University Press, 1995), pp. 319-327.

10 Informal Logic: A Handbook for Critical Argumentation, pp. 194-197.

"Frans H. van Eemeren and Rob Grootendorst, "Argumentum Ad Hominem: A Pragma-Dialectical Case in Point," in Hans V. Hansen and Robert C. Pinto (eds.), op. cit., pp. 223-224.

12 "The Appeal to Popularity and Presumption by Common Knowledge," Hansen and Pinto (ed.), op. cit., p. 268.

Ibid., p. 266 ,

${ }^{14}$ Ibid., pp. 267-268.

is "The Ad Hominem," Hansen and Pinto (eds.), op. cit., pp. 217-218.

${ }^{16}$ Ibid., p. 219.

${ }^{17}$ Ibid., p. 222.

${ }^{18}$ Douglas Walton, Arguments from Ignorance (University Park, Pennsylvania: The Pennsylvania State University Press, 1996), p. 13.

${ }^{19}$ Ibid., p. 118-122.

${ }^{20}$ The Place of Emotion in Argument (University Park: The Pennsylvania State University Press, 1992), p. 1.

2! See Joseph E. LeDoux, "The Neurobiology of Emotion," Mind and Brain: Dialogues in Cognitive Neuroscience, Joseph E. LeDoux and William Hirst, eds. (Cambridge: Cambridge University Press, 1986), Ch. 15. LeDoux argues that the amygdala plays an evaluation or appraisal function, mediating between sensory input and stored information or knowledge. The role of experience and memory in emotional reactions is more prominent than assigned by other theories of emotion. Emotions, therefore, seem to have a much more reasonable, "cognitive" nature. Another interesting neurobiological development of the rationality-of-emotions view is given by Antonio R. Damasio, Descartes' Error: Emotion, Reason, and the Human Brain (New York: Avon Books, 1994), especially Ch. 7. Also see Daniel Goleman, Emotional Intelligence (Bantam Books, 1995).

${ }^{22}$ The Place of Emotion in Argument, pp. 109-117.

${ }^{23}$ Alan Brinton, "The Ad Baculum Re-Clothed," Informal Logic, XIV.2\&3, Spring \& Fall 1992, p. 90.

${ }^{24}$ See for example Douglas Walton, The Place of Emotion in Argument, op. cit, ch. 5. Also, Michael Wreen, "Knockdown Arguments," Informal Logic, XVII, 3, Fall 1995, pp. 316-336.

${ }^{23}$ A point noted by John Woods, "Appeal to Force", in Hansen and Pinto (ed.), op. cit., p. 245.

${ }^{26}$ Cf. Michael Wreen, op. cit., pp. 320-321.

${ }^{27}$ Michael Wreen, op. cit., p. 330.

${ }^{28}$ Cf. Daniel Goleman, op. cit. See, especially, "The Anatomy of Rage," pp. 59m65.

${ }^{29}$ V. Michael McKenzie, "Beating Spousal Battery," Professional Counselor, April, 1996, pp. 15-51. Also see Uma Narayan, "Male-Order Brides: Immigrant Women, Domestic violence, and Immigration Law," Hypatia 10:1, 1995, pp. 106-107.

${ }^{30}$ The Place of Emotion in Argument, op. cit., p. 147

${ }^{31}$ "The Ad Hominem," in Hansen and Pinto (eds.), op. cit., p. 214, n. 1 . 
${ }^{32}$ Robert J. Fogelin and Walter Sinnott-Armstrong, Understanding Arguments: An Introduction to Informal Logic (New York: Harcourt Brace Jovanovich, Publishers, 1991), p. 19.

${ }^{33}$ Ibid., p. 21.

34 Dan Sperber and Deirdre Wilson, Relevance: Communication and Cognition (Cambridge, Massachusetts; Harvard University Press, 1986).

35 "Begging the Question," in Hansen and Pinto (eds.), op. cit., p. 234.

${ }^{36}$ H. P. Grice, "Logic and Conversation," in A. P. Martinich, The Philosophy of Language, 3 rd ed. (New York: Oxford University Press, 1996) pp. 156-167.

${ }^{37}$ Fallacies (London: Methuen \& Co. Ltd., 1970), pp. 14-15.

${ }^{38}$ Hansen and Pinto (eds.), op. cit., pp. 287-301.

${ }^{39}$ From an advertising brochure prepared by the RighTime investment company, "The RighTimes," Fourth Quarter, 1990.

${ }^{40}$ H. P. Grice, op. cit.

${ }^{41}$ Hamblin, op. cit., p. 285.

42 "Missing Premises," Informal Logic, XI.3, Fall 1989.

43 "Enthymematic Arguments," Informal Logic, VI1.2 \& 3, Spring and Fall, 1985, p. 94.

44 "Unstated Premises," Informal Logic, VII. 2 \& 3, Spring \& Fall 1985, pp. 107-118.

${ }^{45}$ Ibid., pp. 107-108.

${ }^{46}$ Douglas Walton is an interesting exception. He often takes a "charitable" approach to reconstructing informal fallacies by allowing for nonfallacious cases and by looking for plausible reconstructions of the reasoning underlying cases of "apparent" fallacy. But he seldom, if ever, refers to the principle of charity to justify or explain his approach. At least, I have so far failed to find such a reference. For example, in Informal Logic, Walton refers to the principle of charity only once, and not in connection with any informal fallacy (op. cit., p. 114). In Argumentation Schemes for Presumptive Reasoning, (op. cit.), references to enthymematic arguments and the principle of charity seem totally absent. This may be due to the belief that dialogue theory, and especially the analysis of presumption, in effect makes such considerations redundant or unnecessary. Thus, for Walton, the justification for doing reconstructions as "argumentation schemes" is grounded in the rest of his approach. My argument is not with Walton, but with others who ignore the principle of charity or any other comparably fair approach to argumentation in dealing with informal fallacies.

${ }^{47}$ Again, as discussed in the previous endnote, this criticism may not apply to Douglas Walton or other advocates of dialogue theory. The relationship between CRM and dialogue theory is a major question to be addressed on another occasion (see Section V). Concerning the present issue, it is clear that dialogue theory is not an opponent.

${ }^{48}$ For example, subjects are presented with a conditional rule "If a card has an A on one side, then it has a 4 on the other side." They are then presented with four cards with "A," "B," " 4 ," and " 7 " showing, and told that the cards all have letters on one side and numbers on the other side. The subjects are then asked which cards must be turned over to determine whether the conditional rule has been violated.

${ }^{49}$ Nisbett, op. cit., p. 186.

so Ibid., p. 230.

st "Do the Fallacies Have a Place in the Teaching of Reasoning Skills or Critical Thinking?," Hansen and Pinto (eds.), op. cit., p. 319.

s2 "The Fallacy Behind Fallacies," Hansen and Pinto (eds.), op. cit., p. 159.

53 In order to provide some simple focus, there has so far been no attention paid to the who question. That is, is the author of the fallacious reasoning, or the audience who accepts the fallacious reasoning (or both), guilty of committing a fallacy? The proposed solution to the demarcation problem also permits an answer this question. Anyone who authors or accepts the fallacious inference is guilty of committing the fallacy; however, it is possible to assign varying 
degrees of guilt depending on the degree and role of culpable deception or ignorance associated with the false premises in the CRM pattern. For example, an advertising copy writer who knowingly and purposely employs subtle equivocal language in order to encourage unsound inferences by the audience deserves a greater measure of disapproval than the audience, though both are guilty of committing the fallacy. In the case of the audience, the assignment of guilt is based on some sense of "they should have seen through that deceptive practice," and will be tempered by the extent to which the equivocation is subtle and difficult to catch.

${ }^{54}$ See excellent examples and discussions of their work in Hans V. Hansen and Robert C. Pinto (eds.), Fallacies: Classical and Contemporary Readings (University Park: The Pennsylvania State University Press, 1995), p. 130-158. Also, see Charles Arthur Willard, A Theory of Argumentation (Tuscaloosa and London: The University of Alabama Press, 1989). And see Douglas N. Walton, Argumentation Schemes for Presumptive Reasoning, cited in n. 1 above.

${ }^{59}$ Acknowledgements: I wish to thank Jonathan Adler and Carol Caraway for their many helpful suggestions on earlier drafts of this paper. Also, I'm very grateful for the insightful and challenging comments of two anonymous referees.

Daniel N. Boone, Department of Philosophy \& Religious Studies Indiana University of Pennsylvania, 451 Sutton Hall Indiana PA 15705-1087 U.S.A. 